\title{
Crustal Structure Beneath Taiwan Using Frequency-band Inversion of Receiver Function Waveforms
}

\author{
DAVid A. TOMFOHRde ${ }^{1}$ and Robert L. NOWACK ${ }^{2}$
}

\begin{abstract}
Receiver function analysis is used to determine local crustal structure beneath Taiwan. We have performed preliminary data processing and polarization analysis for the selection of stations and events and to increase overall data quality. Receiver function analysis is then applied to data from the Taiwan Seismic Network to obtain radial and transverse receiver functions. Due to the limited azimuthal coverage, only the radial receiver functions are analyzed in terms of horizontally layered crustal structure for each station. In order to improve convergence of the receiver function inversion, frequency-band inversion (FBI) is implemented, in which an iterative inversion procedure with sequentially higher low-pass corner frequencies is used to stabilize the waveform inversion. Frequency-band inversion is applied to receiver functions at six stations of the Taiwan Seismic Network. Initial 20-layer crustal models are inverted for using prior tomographic results for the initial models. The resulting 20-1ayer models are then simplified to 4 to 5 layer models and input into an alternating depth and velocity frequency-band inversion. For the six stations investigated, the resulting simplified models provide an average estimate of $38 \mathrm{~km}$ for the Moho thickness surrounding the Central Range of Taiwan. Also, the individual station estimates compare well with the recent tomographic model of RAU and WU (1995) and the refraction results of MA and SoNG (1997).
\end{abstract}

Key words: Taiwan, crustal structure, receiver functions.

\section{Introduction}

Taiwan is located in a complex, tectonically active region at the western margin of the Philippine Sea plate. Collision of the Luzon Arc with the Asian continental margin starting around $5 \mathrm{Ma}$ produced an orogeny which created the island of Taiwan (Teng, 1990). The island can be divided into four general geologic provinces that are shown in Figure 1. Detailed descriptions of the geologic terrains in Taiwan are given by Ho (1979), Teng, (1990), and Hsu (1990).

The physical mechanisms for the Taiwan orogeny has been long debated. SuPPE (1981, 1987) applied the "thin-skinned" tectonic model to the Taiwan orogeny based on detailed mapping of the fold and thrust belt in western Taiwan, as well as

\footnotetext{
${ }^{1}$ Geco-Prakla, 1325 South Dairy Ashford, Houston, TX 77077-2307, U.S.A. E-mail: dtomfohrde@slb.com

${ }^{2}$ Department of Earth and Atmospheric Sciences, Purdue University, West Lafayette, IN 47907, U.S.A. E-mail: nowack@purdue.edu
} 
shallow well data. ROECKER et al. (1987) conducted a three-dimensional tomography study below Taiwan using local earthquakes. Typical subcrustal velocities $(>7.5 \mathrm{~km} / \mathrm{s}$ ) were apparent at $35-50 \mathrm{~km}$ in depth, well below the $20 \mathrm{~km}$ proposed by the "thin-skinned" model. With the recent upgrade of the Taiwan Seismic Network in 1991, high quality three-component data are now available for Taiwan (RAU et al., 1996). Two recent tomography studies have utilized these new data and produced detailed 3-D velocity structures beneath Taiwan (RAU and Wu, 1995; MA et al., 1996). Based on these and other geophysical studies, Wu et al. (1997) proposed the "lithospheric collision" model, where crustal thickness varies from 30 $\mathrm{km}$ and $20 \mathrm{~km}$ on the west and east coasts of Taiwan and to depths greater than $40 \mathrm{~km}$ beneath the Central Range.

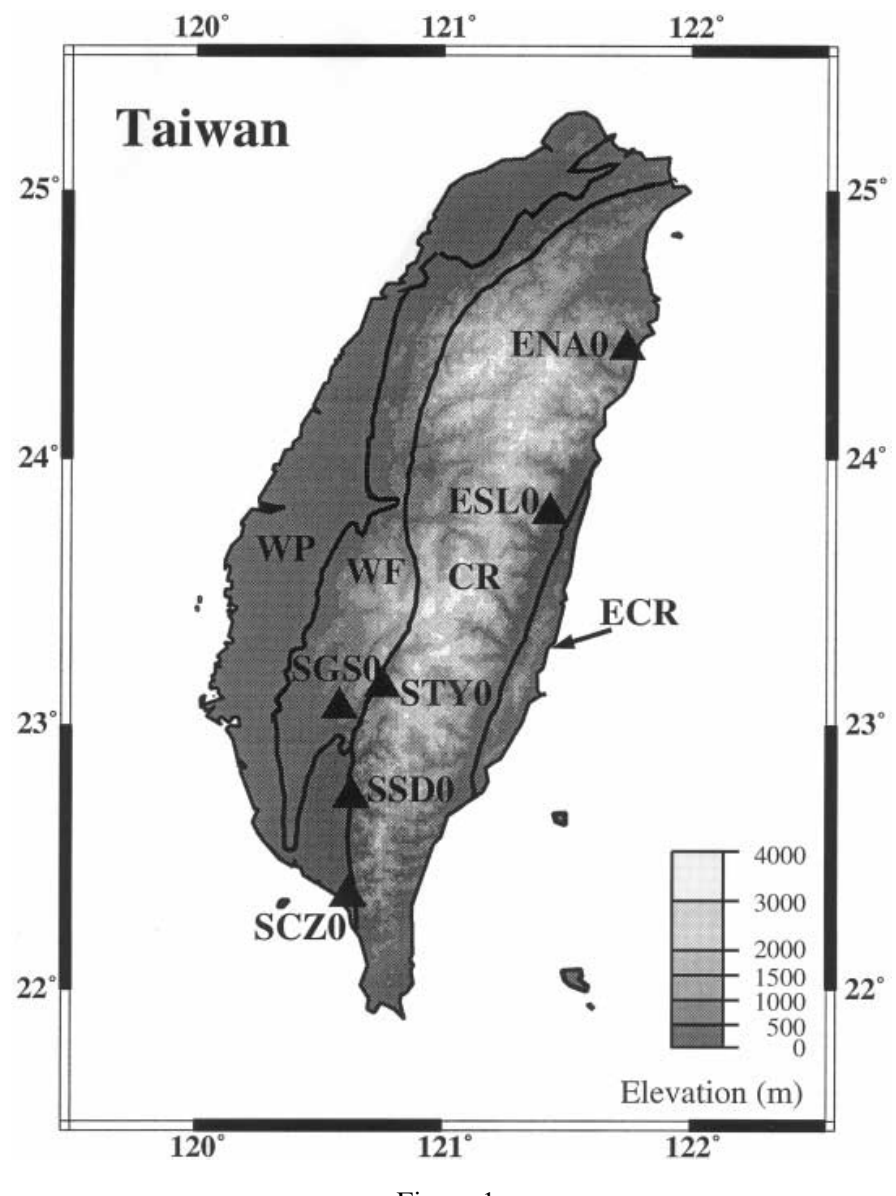

Figure 1

Topographic map of Taiwan. The boundaries of the four main geologic terrains (WF-Western Foothills, WP - Western Coastal Plain, CR - Central Range, ECR - Coastal Range) are noted for reference. Stations for which modeling was performed are labeled and shown with triangle symbols. 
Receiver function analysis has been used to determine lithospheric structure in many tectonic environments (OWEns et al., 1984; CASSIDY and Ellis, 1993; AMmON and Zandt, 1993; RANDAll and Owens, 1994; ZHANG and LANGSTON, 1996). The Taiwan Seismic Network was established to record local seismicity and was not optimized for the recording of teleseismic events. However, by careful selection of stations and events, a useful receiver function dataset can be obtained. To improve convergence for the receiver function waveform inversions, an inversion procedure called frequency-band inversion (FBI) is implemented. The FBI algorithm uses band-pass filtering with sequentially higher low-pass corner frequencies to stabilize the iterative waveform inversion. Frequency-band inversion is then applied to receiver function data from the Taiwan Seismic Network to obtain crustal structure beneath Taiwan.

\section{Data Analysis}

The data used for this study were recorded by the Taiwan Seismic Network, which consists of approximately 75 stations and was operated formerly by the Institute of Earth Science, Academia Sinica and currently by the Central Weather Bureau, Taipei, Taiwan. The stations are short-period with a resonant frequency of $1 \mathrm{~Hz}$. Nonetheless, useful signal can be obtained for frequencies down to approximately one-tenth of the resonant frequency. The data used in this study were recorded between 1991 and 1994 and are sampled at 100 sps. Since the Taiwan Seismic Network was not optimized for the recording of teleseismic events, each station was carefully examined for high noise content, digitization effects and other anomalous features, and stations with significant contamination were discarded. Polarization characteristics were also used for the assessment of data quality. The selected stations used in this study are shown in Figure 1. An initial set of 49 events were chosen, with source to receiver distances greater than 30 degrees. The event locations are plotted in Figure 2 where the epicenters are shown by solid circles, the center of the Taiwan Seismic Network is labeled, and source-receiver paths are shown. These earthquakes can be grouped into two backazimuth ranges, one to the northeast and one to the south of Taiwan.

\section{Receiver Functions}

Receiver function analysis was used to estimate the crustal structure beneath individual three-component stations. For a more detailed description of the method, see LANGSTON (1979), OwENS et al. (1984), AMMON et al. (1990), or CASsIDY (1992). By using teleseismic waves, the incident $P$-wave can be approximated by a plane wave incident on the structure from below. As the incident 


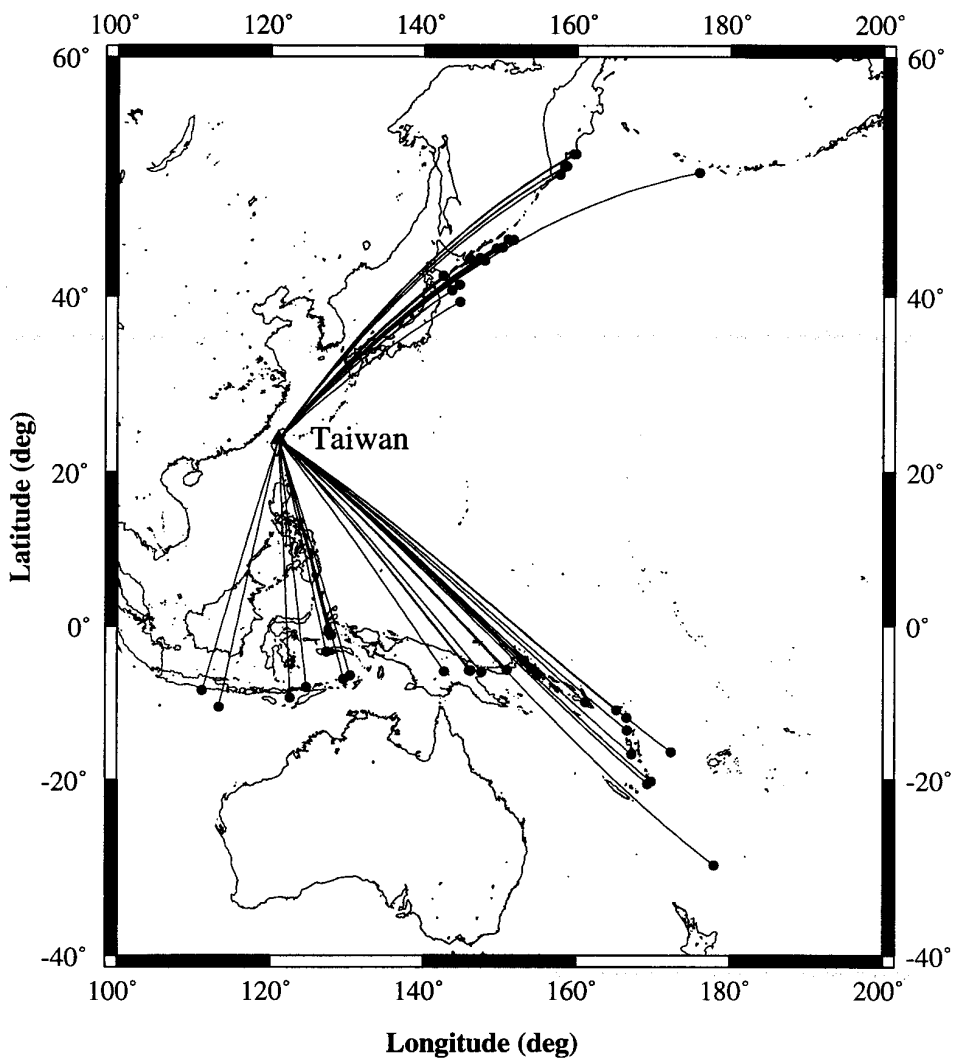

Figure 2

Map of earthquake locations used in the receiver function study of Taiwan. Solid circle symbols show the locations of epicenters and lines represent source to receiver paths.

$P$-wave travels through the upper mantle and crust below the recording station, velocity contrasts are encountered and produce converted $S$-waves. The converted phases can be seen and identified because they appear mainly on the radial horizontal component for an elastic, plane layered crust. Deconvolution of the horizontal components by the vertical component produces the radial and transverse receiver functions. The dominant first arrival on the radial receiver function is leakage of the direct $P$-wave onto the radial component. Later arrivals are $P$-to- $S$ conversions within the crust, as well as other crustal multiples.

Because of the consistency of the receiver functions for events with different source-time functions, distances, and backazimuths (OwENs et al., 1984), the technique can be used for a suite of events recorded by a three-component seismic station. Nonetheless, the earth structure beneath a seismic station may be slightly different, depending on the azimuth of the incident $P$-wave, and therefore the 
receiver functions may vary somewhat with respect to azimuth and distance. For events with similar backazimuths, receiver functions can be normalized, aligned, and stacked to obtain a stable, average receiver function. The stacking procedure also provides an estimate of the bounds on the average receiver function for a range of backazimuths. These bounds allow for the determination of which phases are well constrained by the average receiver function. The synthetic seismograms for a given velocity model are then required to match the average receiver function within those bounds.

\section{Taiwan Receiver Functions}

Radial and transverse receiver functions are obtained for several stations from the Taiwan Seismic Network, using the method described above. Events are grouped into two backazimuth ranges, one to the northeast and one to the south. Three-component, short-period data for each event are filtered with a low-pass Butterworth filter with a corner frequency of $1.0 \mathrm{~Hz}$, and the horizontal components are rotated into radial and transverse components. A damped least-squares deconvolution procedure is used to obtain the radial and transverse receiver functions. Figure 3 displays the results for station ESL0 for the south backazimuth. The plot on the left shows the radial receiver function for several events, with the event designation labeled to the right of each trace. The average receiver function is obtained by stacking individual events and is shown at the top of the plot. Also shown by the grey shaded area is the average receiver function plus or minus one standard deviation for each point in the average trace. These bounds provide constraints on individual phases seen on the average receiver function. The plot on the right shows the transverse receiver functions plotted at the same scale as the radial receiver function. The average transverse receiver function and one standard deviation bounds are shown at the top of the plot. The stacking results for other stations are given by TOMFOHRDE (1998).

\section{Receiver Function Modeling}

A common assumption in receiver function modeling is that the crustal structure beneath a recording station is composed of plane layers. For isotropic, horizontally layered media, $P$-to- $S$ conversions result in $S V$ phases, which are seen only on the radial component receiver function. For this case, the transverse receiver function should contain no converted $S$-wave information, and the amplitude on the transverse component can be used to validate this assumption. However, $P$-SH conversions are commonly observed on teleseismic $P$-waveforms (LEVIN and PARK, 1997). Typical explanations for $P$-SH conversions include ray divergence from the great-circle path due to lateral velocity heterogeneities (Hu and MENKE, 1992), the presence of dipping isotropic layers beneath the receiver 
A)

Radial Receiver Function

FED FE21
B)

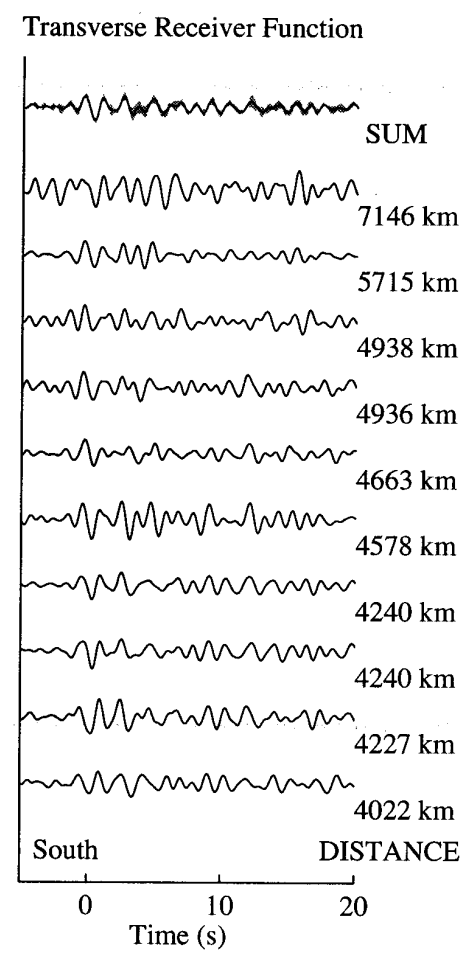

Figure 3

Filtered radial and transverse receiver functions for station ESL0 for the south backazimuth. A) Radial receiver functions with the event designation labeled to the right of each trace. The SUM trace (solid line) is obtained by stacking the individual receiver functions. The grey shaded area shows the one standard deviation bounds. B) Transverse receiver functions for the same events. The SUM trace and bounds are again shown at the top of the plot. The event distance is shown to the right.

(LANGSTON, 1977; CASsidy, 1992), scattering from topography on the surface or on velocity interfaces beneath the station (CLOUSER and LANGSTON, 1995), and plane layered anisotropy (MCNAMARA and OWENS, 1993; LEVIN and PARK, 1997). In the context of receiver function modeling, the most common explanations for $P-S H$ conversions is the presence of dipping layers and anisotropy. Both effects are modeled by the azimuthal variation of the transverse receiver functions. Examination of the transverse receiver functions indicates that for the interpreted $P S$ phases from the Moho, there are corresponding peaks on the transverse receiver functions. This can be seen in the average transverse receiver function for station ESL0 at $t=4 \mathrm{~s}$ in Figure 3. This may indicate the presence of scattering from laterally varying structure or anisotropy beneath Taiwan (CASSIDY, 1992). As can be seen in Figure 2, the azimuth range of the data used in this study is limited to two 
backazimuth ranges. Therefore we did not model the effects of lateral heterogeneity or anisotropy, and only the radial receiver functions were modeled for a horizontally layered isotropic crustal structure beneath each station.

\section{Frequency-band Inversion}

To improve convergence when using waveform data, we implemented an inversion procedure called frequency-band inversion or FBI. The frequency-band inversion (FBI) algorithm uses band-pass filtering with sequentially higher low-pass corner frequencies in order to stabilize the iterative waveform inversion. For the first frequency band, the observed and synthetic receiver functions are filtered within a particular frequency bandwidth. An iterative, damped least-squares procedure is then performed to find layer thickness or layer velocity parameters. The final model in one frequency band is then used as the initial model for the following frequency band. For the next frequency band, the upper cutoff frequency is increased and the inversion is repeated.

In our implementation of the frequency-band inversion, the number of frequency bands and the upper corner frequencies used were chosen by the user and the low corner frequency remained fixed. The motivation for using a multiple frequency-band inversion over a single inversion is that at lower frequencies, the longer wavelength structure can be determined. As the upper cutoff frequency is increased, more detail is added. TOMFOHRDE (1998) presents results of synthetic testing of the frequency-band inversion method. However, for the multiple frequency-band inversion procedure, the computation time is correspondingly increased.

\section{Frequency-band Inversion of Taiwan Data}

In modeling the observed receiver functions from the Taiwan Seismic Network, we wanted the simplest models which fit the observed waveform data. As a first step, a 20-layer model is constructed from the prior tomographic results of ROECKER et al. (1987) and RAU and WU (1995). Most tomographic studies obtain $P$-wave velocity models, however receiver function analysis is most sensitive to $S$-wave velocities. A Poisson solid is therefore assumed so that starting $S$-wave velocity models can be obtained from the $P$-wave velocity models. The initial velocity models are divided into 2 to $3 \mathrm{~km}$ thick layers and the initial layer velocities are derived from the tomography models. An inversion is then performed for layer velocities using a frequency-band inversion (FBI) with layer thicknesses held constant. For this study four frequency bands were chosen with upper cutoff frequencies of $0.6,0.7,0.8$, and $1.0 \mathrm{~Hz}$ and a lower cutoff frequency of $0.1 \mathrm{~Hz}$. Because of the small layer thicknesses, the character of the resulting models appears 
similar to those obtained from other receiver function studies (OwENS et al., 1984; CASsidy, 1992; RANDALl and Owens, 1994; AMmon and ZandT, 1993), where the models are very step-like and contain several low velocity zones. Using these results, adjacent layers with similar seismic velocities are manually grouped together to obtain simplified 3 to 5 layer models. These are then used as initial models in an alternating depth and velocity FBI inversion. For the alternating depth and velocity inversion, within each frequency band an inversion is completed for layer thickness parameters and is followed by an inversion for layer velocities. The resulting simplified models are then interpreted in terms of intermediate crustal and Moho depths, and compared to the previous crustal models for Taiwan.

\section{Station ESLO}

Station ESL0 is located in central eastern Taiwan on the eastern flank of the Central mountain range (Fig. 1). The radial and tangential receiver functions for the south backazimuth are shown in Figure 3. A 20-layer model is constructed using 2 to $3 \mathrm{~km}$ thick layers, with the layer velocities derived from the prior tomographic studies of ROECKER et al. (1987) and RAU and WU (1995). A frequency-band inversion (FBI) is used first to invert for layer velocities while maintaining constant layer thicknesses. The results are shown in Figures 4A,C where a Poisson solid is assumed in relating $P$ - and $S$-wave velocities. The observed receiver function for events to the south of Taiwan is illustrated with a solid line in Figure $4 \mathrm{~A}$, with the grey shaded area corresponding to the data errors obtained during the stacking of the data. A dashed line delineates receiver function calculated from the final model. Also noted on the plot is the average data error and the RMS misfit, where the RMS misfit is now within the average data error. The corresponding velocity models are shown in Figure 4C, where the prior tomographic models of RoECKER et al. (1987) and RAU and Wu (1995) are shown with short and long dashed lines, respectively. The starting model is depicted with a thin solid line and the resulting final model is shown with a thick solid line. The general character of the waveform has been matched, namely that all the major peaks observed in the waveform fit with a peak in the inversion result. The resulting velocity model is generally smooth, with small steps at about 10,20 and $35 \mathrm{~km}$ in depth.

Based on the results of the 20-layer FBI, layers were then grouped into four layers as shown in Figure 4D, where the thick and thin solid lines are the simplified and 20-layer model, respectively. The initial 4-layer model was then input into an alternating depth and velocity FBI, and the results are shown in Figures 4B,E. The modeling results from the 20-layer model are shown in Figures 4A,C for comparison with the simplified model results. To further examine the waveform fit, Figure 4B is enlarged and shown in Figure 5. The character of the observed receiver function (solid line) is also well matched by the simplified model inversion results 

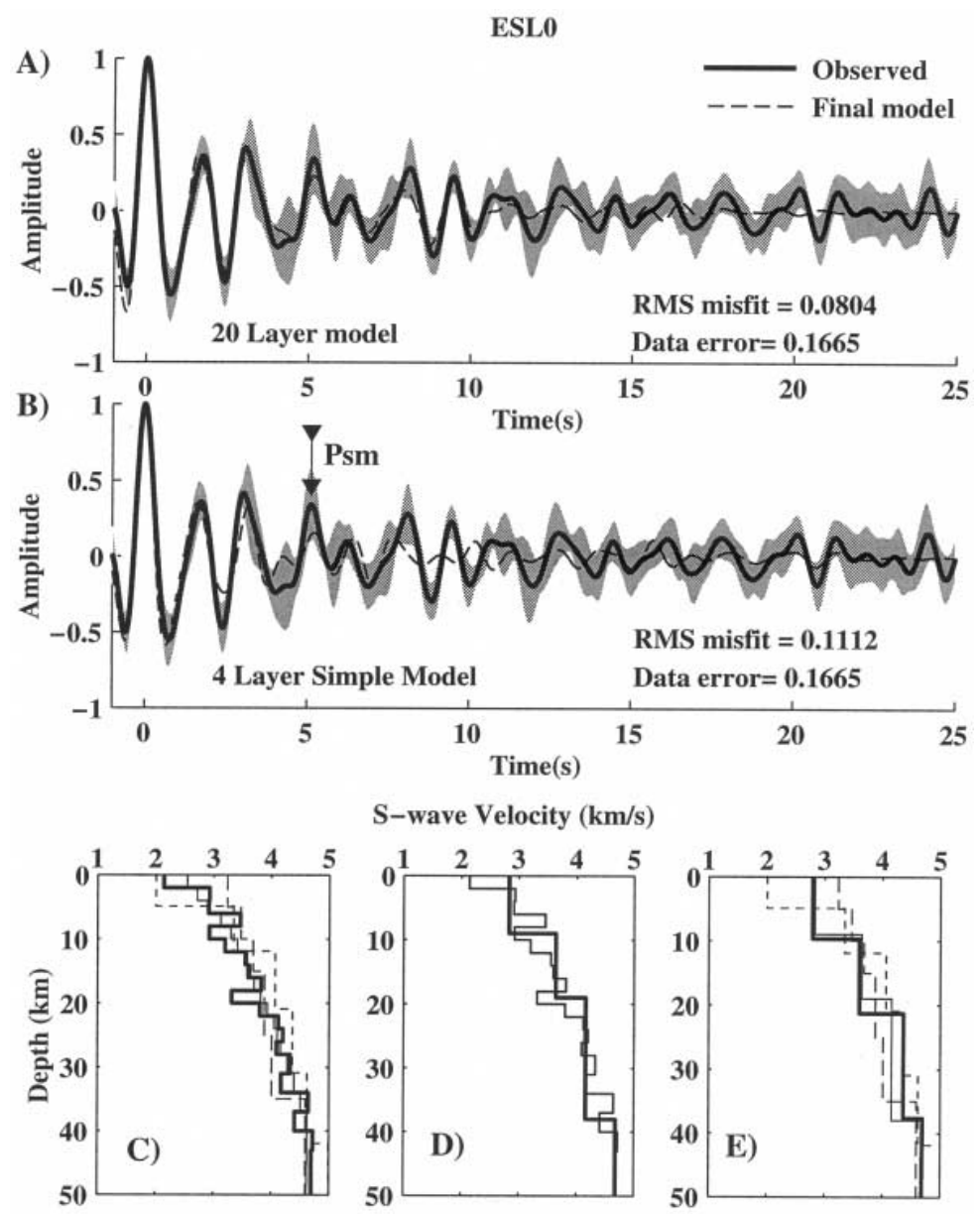

Figure 4

Frequency-band inversion results for station ESL0 for the south backazimuth. A) 20-layer velocity only FBI. B) 4-layer alternating depth and velocity FBI. The solid line and grey shaded area are the observed receiver function and the one standard deviation stacking bounds. The dashed line corresponds to the final model receiver function. Noted on each plot is the final RMS misfit for comparison to the data errors. C) $S$-wave velocity models for 20-layer FBI. D) Comparison of 20-layer final model (thin solid line) with initial simplified model (thick solid line). E) $S$-wave velocity models for the 4-layer alternating FBI. In C) and E) initial and final models are shown as thin and thick solid lines with the tomographic models of RAU and WU (1995) and ROECKER et al. (1987) shown by short and long dashed lines, respectively.

(dashed line) in Figure 5. The observed waveform is fit well for the first 8 seconds, over which the $P S$ converted phases arrive. Each $P S$ phase is labeled as $P X s$, where $X$ denotes the interface at which the conversion occurs and the interfaces are numbered starting at 1 at the first interface below the surface and increasing with 
depth. Several later peaks in the waveform are also matched by the model receiver function including $P p P 3 s$ and $P s P 3 s$ where these correspond to multiple reverberations within the crust. For example, the $P p P 3 s$ phase represents a $P$-wave incident on the crust from below (first capital $P$ ), propagates as a $P$-wave to the surface (small $p$ ), is reflected at the surface to a downgoing $P$-wave (second capital $P$ ), is reflected at some interface (interface 3 for this case), and travels back to the surface as an $S$-wave (small $s$ ). For this case the $P p P 3 s$ and $P s P 3 s$ phases calculated from the final simplified model are aligned with larger amplitude peaks on the observed waveform. A comparison with individual phases is used to check the quality of the waveform fit, in addition to the overall RMS misfit. The amplitude of the modeled Moho Ps phase (Psm, Fig. 4B) is within the error bounds but lower in amplitude than the observed phase. This may be due to interference with multiples from other layers within the crust or alternatively, the $S$-velocity contrast for this station must be somewhat greater than obtained from the inversion.

As expected, the RMS misfit has increased somewhat by using the 4-layer simplified model compared to the 20-layer model. However, the number of model parameters has decreased from 20 (velocities) to 7 (4 velocity and 3 layer thicknesses) and the RMS misfit remains less than the data errors. Thus, by allowing a slight increase in the average model misfit, we have obtained a greatly simplified crustal velocity model.

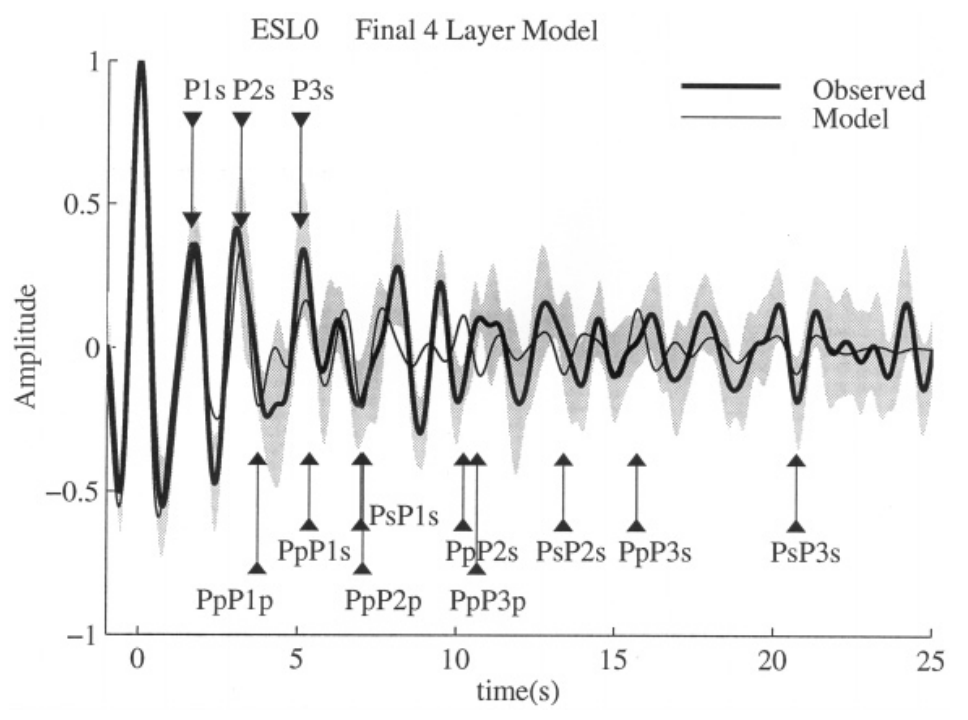

Figure 5

Inversion results for the four layer model for station ESL0 for the south backazimuth. The observed receiver function (dark solid line) is shown with one standard deviation bounds (grey shaded area) and final model receiver function (thin solid line). Important $P$-to- $S$ conversions and multiple phases are labeled and shown with arrows. Each of the $P s$ phases and multiple arrivals fit the waveform well with the exception of $P p P 2 s$ and $P p P 3 p$. 


\section{Station STYO}

Station STY0 is located on the western side of the central mountain range on the boundary of the Central Range and Western Foothills provinces in south-central Taiwan (Fig. 1). Receiver functions for this station were obtained for both the northeast and south backazimuth ranges. The average receiver function for the south backazimuth is designated by the solid lines in Figures 6A,B, and the grey shaded data errors are obtained from the stacking of the data. The first step in the modeling procedure is to construct a 20-layer model with 2 to $3 \mathrm{~km}$ thick layers. The initial velocities were chosen to correspond to the prior tomographic studies of Roecker et al. (1987) and RAU and Wu (1995), and a Poisson solid is assumed. The initial 20-layer model is input into a velocity only FBI and Figure 6C shows the initial model (thin solid line) and the resulting 20-layer model (thick solid line). Long and short dashed lines signify the tomographic results of ROECKER et al. (1987) and RAU and WU (1995), respectively. The final model receiver function is shown in Figure 6A with a dashed line. Note that the model receiver function fits the observed waveform well and the RMS misfit is lower than the data errors.

The final 20-layer model is then simplified by grouping adjacent layers with similar velocities, which for this station results in a 5-layer model with velocity contrasts at 4, 12, 30 and $40 \mathrm{~km}$ in depth. The simplified model is then used as an initial model for an alternating depth and velocity FBI. The final model receiver function is shown in Figure 6B. The observed waveform is reasonably matched by the final model within the one standard deviation stacking bounds for the first 7 seconds following the direct $P$-wave. The large peak at $16 \mathrm{~s}$ is matched by the $P p P 4 s$ multiple calculated from the resulting simplified model. Note that the velocity contrast at the second and third interfaces are small, and hence the multiple phases reflected at these interfaces are small. There is a large phase near one second that is not modeled by the simple model. This may be due to scattering of the first arrival energy or interference of the first arrival with $P S$ phases within the crust. Also, the amplitude of the Moho Ps phase is less than the observed, possibly suggesting that a greater $S$-velocity contrast is needed. The RMS misfit for the final simplified model has increased compared to the 20-layer model, however the RMS misfit still remains less than the data error. By allowing a slight increase in RMS misfit, we have simplified the crustal model from 20 parameters to 9 parameters (5-layer velocities and 4-1ayer thicknesses) while maintaining a reasonably good waveform fit.

The above procedure was repeated for the north backazimuth at station STY0. The resulting 20-layer model is similar to the south backazimuth except that the step at the Moho is at $39 \mathrm{~km}$ rather than $42 \mathrm{~km}$. The resulting model receiver functions for both the 20 layer and simplified models match the observed receiver function within the grey shaded one standard deviation bounds for the Ps converted phase arrivals. The RMS misfit for the 5-layer model has increased 30 percent compared to the final 20-layer model, but both are less than the data error. 

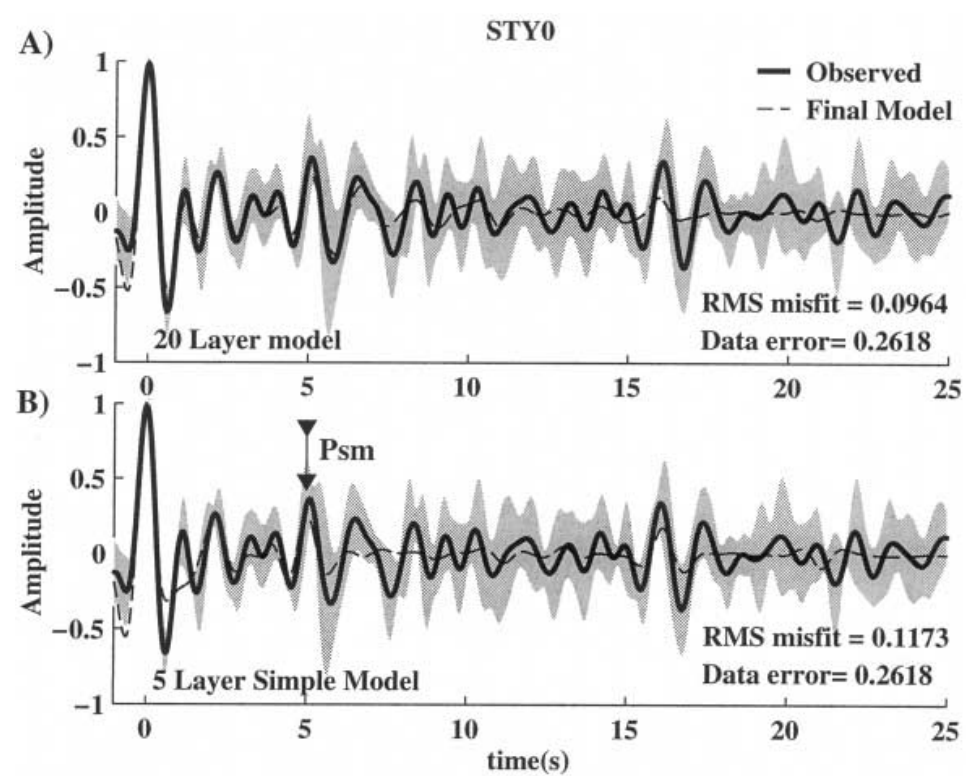
S-wave Velocity $(\mathrm{km} / \mathrm{s})$
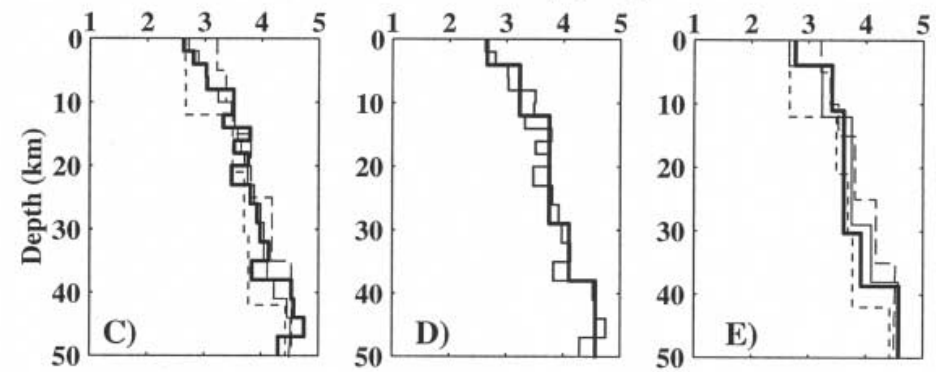

Figure 6

Frequency-band inversion results for station STY0 for the south backazimuth. A) 20-layer velocity only FBI. B) 5-layer alternating depth and velocity FBI. The solid line and grey shaded area are the observed receiver function and the one standard deviation stacking bounds. The dashed line corresponds to the final model receiver function. Noted on each plot is the final RMS misfit for comparison to the data errors. C) $S$-wave velocity models for 20-layer FBI. D). Comparison of 20-layer final model (thin solid line) with initial simplified model (thick solid line). E) $S$-wave velocity models for the 5-layer alternating FBI. In C) and E) initial and final models are shown as thin and thick solid lines with the tomographic models of RAU and WU (1995) and ROECKER et al. (1987), shown by short and long dashed lines, respectively.

\section{Station ENAO}

Station ENA0 is located on the northeastern coast of Taiwan within the Central Range province (see Fig. 1). For this station, receiver functions were only obtained 
for the south backazimuth range. A 20-layer model was constructed using 2 to $3 \mathrm{~km}$ thick layers and velocities, and those layers were taken from the tomographic models of RoECKER et al. (1987) and RAU and WU (1995). The initial model for a velocity only FBI and the results are displayed in Figure 7. Figure 7A shows the observed receiver function (solid line), the one standard deviation bounds obtained
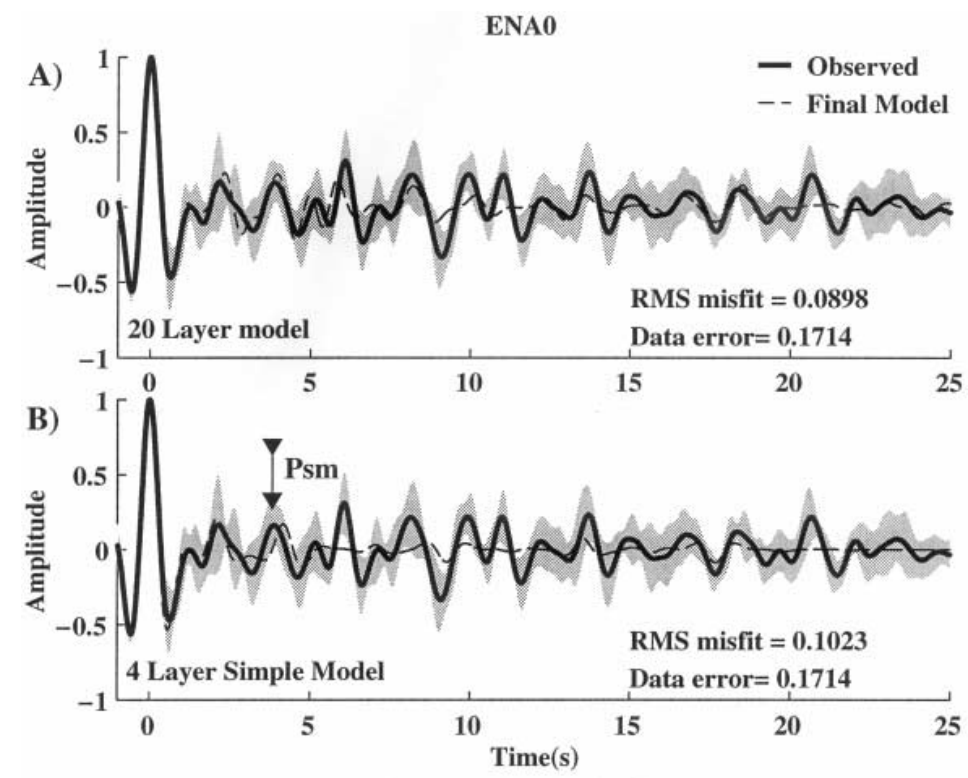

S-wave Velocity $(\mathrm{km} / \mathrm{s})$
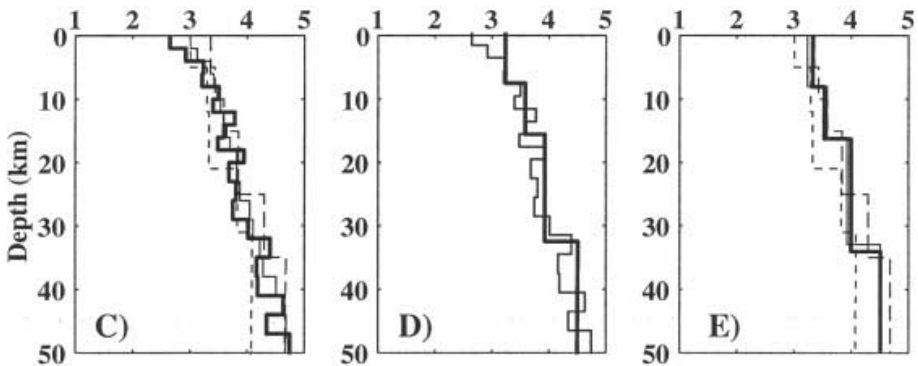

Figure 7

Frequency-band inversion results for station ENA0 for the south backazimuth. A) 20-layer velocity only FBI. B) 4-layer alternating depth and velocity FBI. The solid line and grey shaded area are the observed receiver function and the one standard deviation stacking bounds. The dashed line corresponds to the final model receiver function. Noted on each plot is the final RMS misfit for comparison to the data errors. C) $S$-wave velocity models for 20-layer FBI. D) Comparison of 20-layer final model (thin solid line) with initial simplified model (thick solid line). E) $S$-wave velocity models for the 4-layer alternating FBI. In C) and E) initial and final models are shown as thin and thick solid lines with the tomographic models of RAU and WU (1995) and ROECKER et al. (1987), shown by short and long dashed lines, respectively. 
through stacking (grey shaded area), and the final model receiver function (dashed line). The observed receiver function is well matched for the first 10 seconds following the first arrival, and also for several later peaks, and the RMS misfit is below the average observed data error. The resulting velocity model is shown in Figure 7B (thick solid line) with the initial model (thin solid line) and the tomographic models of ROECKER et al. (1987), (long dashed line) and RAU and WU (1995), (short dashed line). The resulting model has several low velocity layers, but there are also velocity increases at 8,16 , and $33 \mathrm{~km}$.

Based on the 20-layer model, a simplified 4-layer model was constructed by grouping layers of similar velocities. This model was input into an alternating depth and velocity FBI and the results are presented in Figure 7. Figure 7D shows a comparison of the 20-layer model (thin solid line) and the 4-layer model (thick solid line). Figure 7B shows the observed receiver function (solid line), error bounds (grey shaded area), and the final model receiver function (dashed line). The observed waveform is reasonably well modeled for the first 5 seconds and several later peaks match well with modeled multiple phases. The modeled Moho Ps phase has similar amplitude to the observed but slightly shifted in time. This may suggest that the Moho may be slightly shallower for this station than obtained from the inversion. Also, several phases between 6 and 11 seconds are not fit by the inversion. Based on the amplitude of the $P s$ phases, these are too large to be multiple phases and may result from stacking problems in the data processing or unmodeled phases due to lateral heterogeneity or scattering. The RMS misfit has increased $14 \%$ for the simplified model inversion with a decrease in the number of model parameters from 20 to 7. By allowing a slight increase in the RMS misfit, we have obtained a simplified model which fits the observed receiver function within the data errors.

\section{Station SSDO}

Station SSD0 is located in southern Taiwan on the western edge of the Central Range province noted in Figure 1. Receiver functions were obtained for the northeast and south backazimuth ranges. The average radial receiver function for the south backazimuth is shown in Figures $8 \mathrm{~A}, \mathrm{~B}$ by a solid line with the grey shaded one standard deviation bounds obtained during stacking. A 20-layer model was chosen and input into a frequency-band inversion for velocity and the results are shown in Figures 8A,C. The final model receiver function is shown with a dashed line in Figure 8A and matches the observed receiver function well over the first 7 seconds. The final 20-layer model is shown in Figure 8C (thick solid line) with the initial 20-layer model (thin solid line) and the tomographic models of RAU and WU (1995) and RoEcKer et al. (1987), (short and long dashed lines, respectively). The final 20-layer model (thick solid line, Fig. 8C) has velocity increases at 4,26 , and $38 \mathrm{~km}$ depth and thus the simplified model was chosen with 4 layers. A 

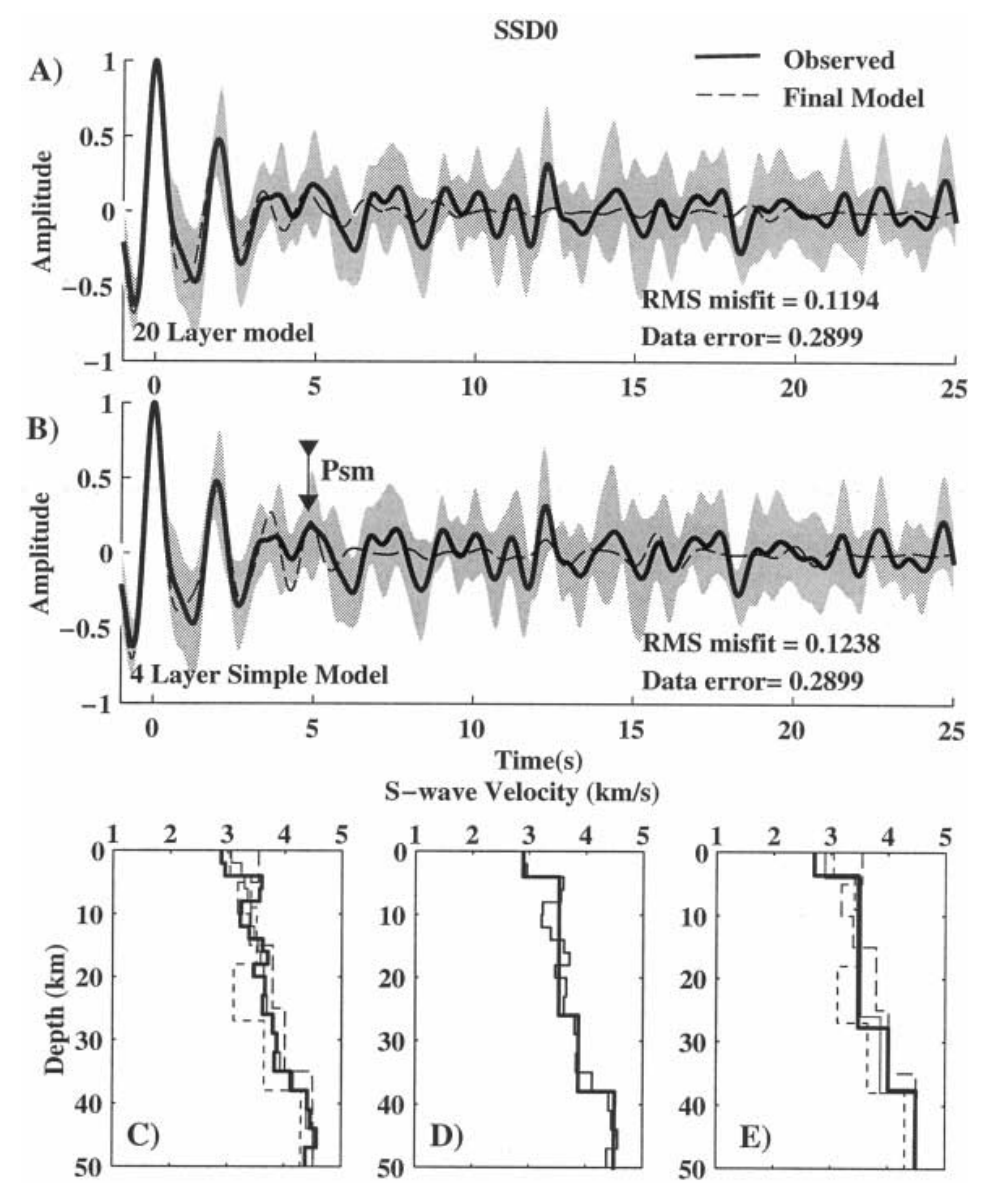

Figure 8

Frequency-band inversion results for station SSD0 for the south backazimuth. A) 20-layer velocity only FBI. B) 4-layer alternating depth and velocity FBI. The solid line and grey shaded area are the observed receiver function and the one standard deviation stacking bounds. The dashed line corresponds to the final model receiver function. Noted on each plot is the final RMS misfit for comparison to the data errors. C) $S$-wave velocity models for 20-layer FBI. D) Comparison of 20-layer final model (thin solid line) with initial simplified model (thick solid line). E) $S$-wave velocity models for the 4-layer alternating FBI. In C) and E) initial and final models are shown as thin and thick solid lines with the tomographic models of RAU and WU (1995) and ROECKER et al. (1987), shown by short and long dashed lines, respectively.

comparison of these two models is presented in Figure 8D where the final 20-layer model and initial 4-layer models are shown with thin and thick solid lines. The initial simplified model is input into an alternating depth and velocity FBI. The resulting model receiver function (Fig. 8B, dashed line) fits the $P s$ phases reasonably well and also fits several later peaks with multiple phases. The large arrival at 
$2 \mathrm{~s}$ is the result of free surface multiples from the velocity contrast near $3 \mathrm{~km}$ depth. As expected, the RMS misfit increases compared to the final 20-layer model, but is less than the average data error.

The procedure described above for the south backazimuth was repeated using the receiver function for the north backazimuth. The stacking result for the north and south backazimuths are slightly different. Several low velocity layers are present along with velocity increases at $4,10,28$, and $38 \mathrm{~km}$ in depth. A simplified 5-layer model was chosen with interfaces and velocities based on the velocity increases seen on the final 20-layer model (ToMFOHRDE, 1998, Fig. 6.8). The initial simplified model is then used as the starting model for an alternating depth and velocity FBI. The final model receiver function roughly fits the first 5 seconds of the observed receiver function. Additionally, several later peaks are fit by multiple phases.

\section{Station SCZO}

Station SCZ0 is located near the southern tip of Taiwan (Fig. 1). Radial and transverse receiver functions were obtained for the south backazimuth. The procedure described for the previous stations was repeated for this station and the results are shown in Figure 9. The final 20-layer model (thick solid line, Fig. 9C) has velocity increases at $8,18,29$, and $38 \mathrm{~km}$ depth and a 5-layer simplified model was chosen. The final 20-layer model (thin solid line) and chosen 5-layer model (thick solid line) are displayed for comparison in Figure 9D. The simplified model is used as an initial model for an alternating depth and velocity FBI and the results are shown in Figures 9B and E. The resulting model receiver function (Fig. 9B, dashed line) matches the $P s$ phases, which occur in the first 5 seconds, and 2 multiple phases fit later peaks. There are several phases after the $P s$ phases, which are not modeled by the inversion of the simple model. This may be the result of scattering or stacking problems in data processing.

\section{Station SGSO}

Station SGS0 is located in southwestern Taiwan in the Western Foothills province (Fig. 1). Radial and transverse receiver functions were obtained for the northeast and south backazimuths ranges. The procedure described for previous stations is repeated for this station and the results are described below.

The results for the north backazimuth are shown in Figure 10. The final 20-layer model (Fig. 10C, thick solid line) varies smoothly with depth with small velocity increases at 10,16, 23, 29, and $41 \mathrm{~km}$ depth. These results were simplified to a 5-layer model (see Fig. 10D for comparison). The results of an alternating depth and velocity FBI, using the simplified model as an initial model, are shown in Figures $10 \mathrm{~B}$ and $\mathrm{E}$. The resulting model receiver function (Fig. 10B, dashed line) 
fits the observed waveform well for the first 6 seconds where the $P s$ phases occur, and several later peaks are fit by multiple arrivals. There are several phases after the Ps phases, which are not modeled by the inversion, which may be due to scattering or lateral heterogeneities. The RMS misfit increased approximately 20 percent compared to the final 20-layer model, nonetheless the RMS misfit remains less than the average data error.
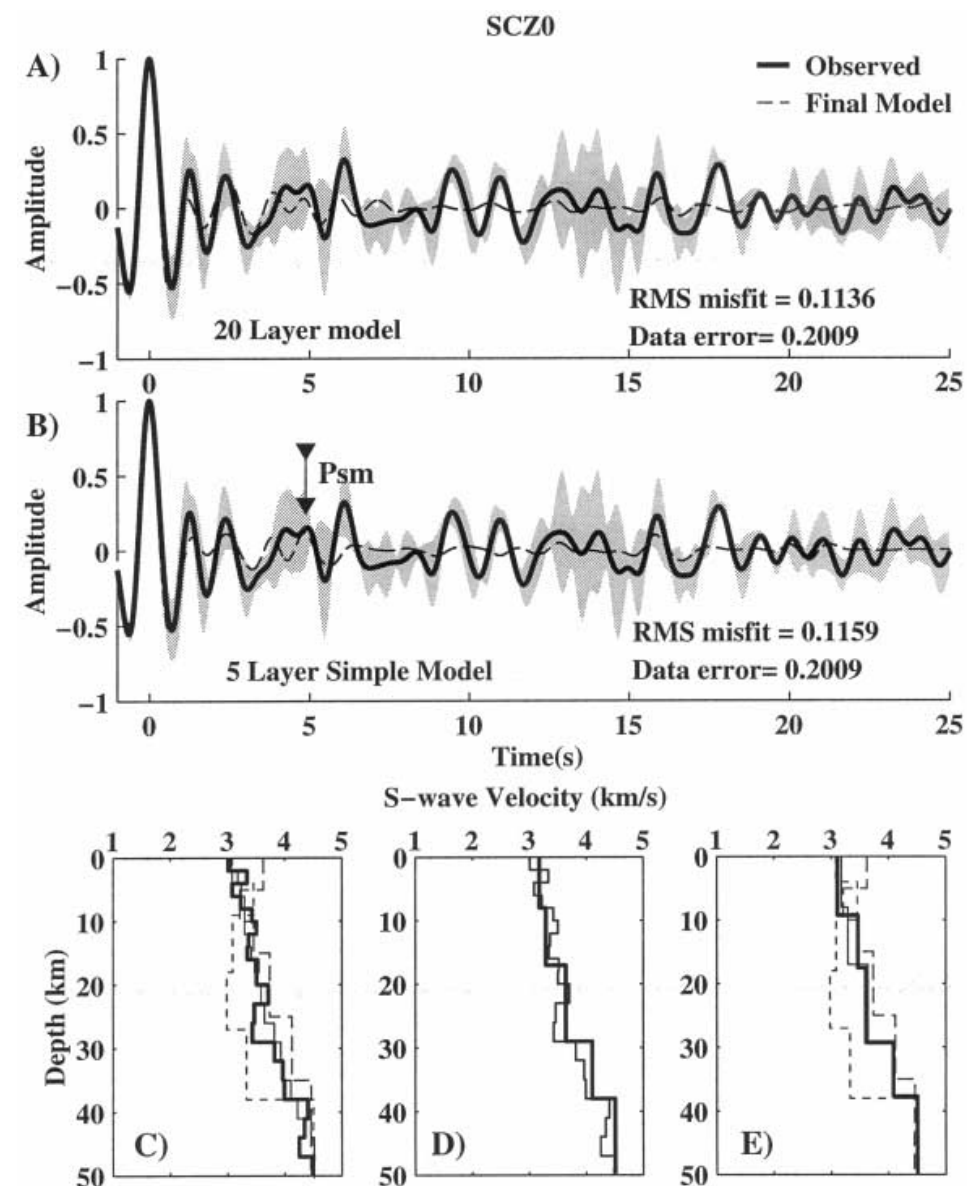

S-wave Velocity $(\mathrm{km} / \mathrm{s})$
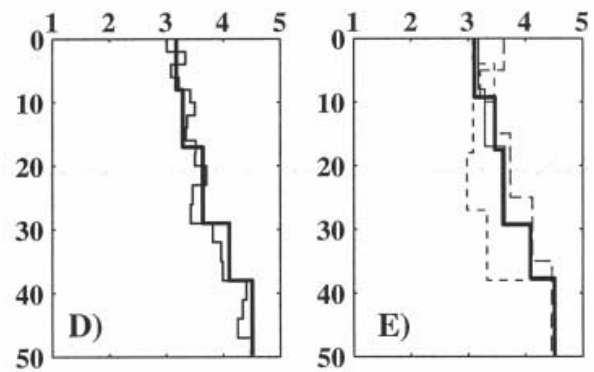

Figure 9

Frequency-band inversion results for station SCZ0 for the south backazimuth. A) 20-layer velocity only FBI. B) 5-layer alternating depth and velocity FBI. The solid line and grey shaded area are the observed receiver function and the one standard deviation stacking bounds. The dashed line corresponds to the final model receiver function. Noted on each plot is the final RMS misfit for comparison to the data errors. C) $S$-wave velocity models for 20-layer FBI. D) Comparison of 20-layer final model (thin solid line) with initial simplified model (thick solid line). E) $S$-wave velocity models for the 5-layer alternating FBI. In C) and E) initial and final models are shown as thin and thick solid lines with the tomographic models of RAU and WU (1995) and ROECKER et al. (1987), shown by short and long dashed lines, respectively. 

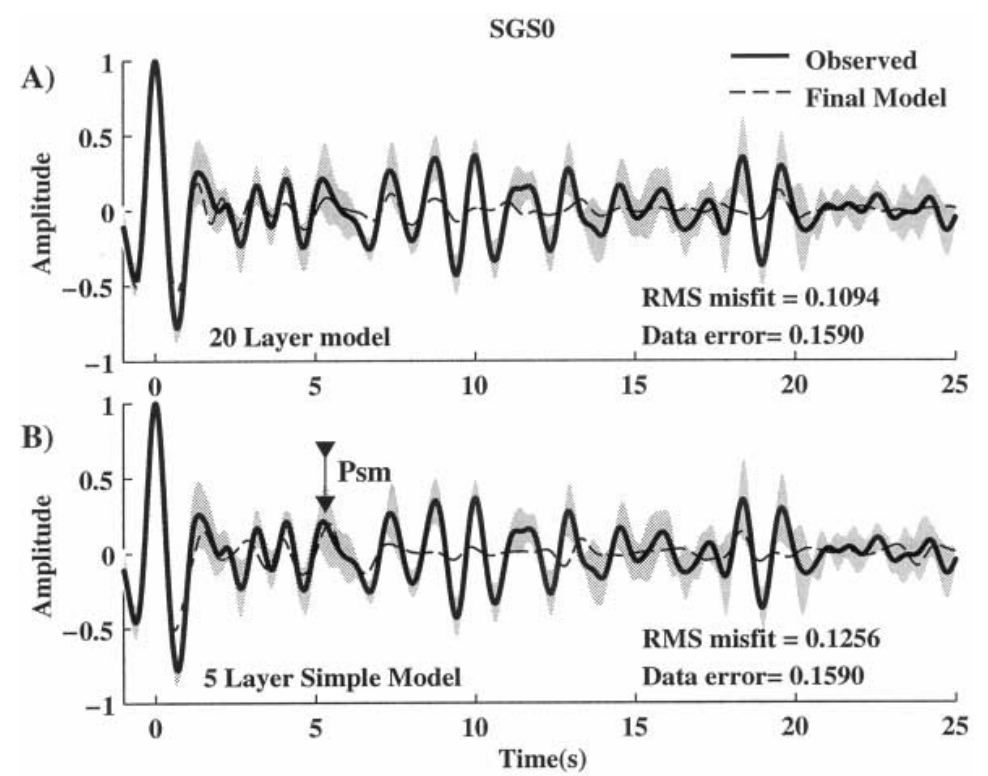

S-wave Velocity $(\mathrm{km} / \mathrm{s})$
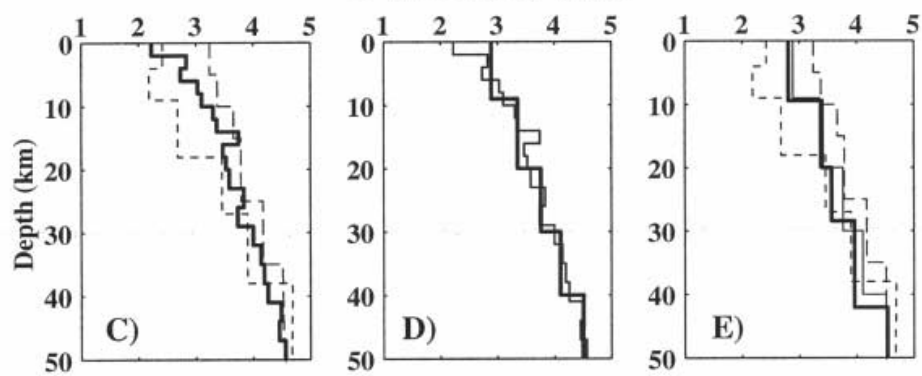

Figure 10

Frequency-band inversion results for station SGS0 for the north backazimuth. A) 20-layer velocity only FBI. B) 5-layer alternating depth and velocity FBI. The solid line and grey shaded area are the observed receiver function and the one standard deviation stacking bounds. The dashed line corresponds to the final model receiver function. Noted on each plot is the final RMS misfit for comparison to the data errors. C) $S$-wave velocity models for 20-layer FBI. D) Comparison of 20-layer final model (thin solid line) with initial simplified model (thick solid line). E) $S$-wave velocity models for the 5-layer alternating FBI. In C) and E) initial and final models are shown as thin and thick solid lines with the tomographic models of RAU and WU (1995) and ROECKER et al. (1987), shown by short and long dashed lines, respectively.

The analysis was repeated for the south backazimuth receiver function. The final 20-layer model has a large velocity increase at $4 \mathrm{~km}$ depth, a high velocity layer at $14-16 \mathrm{~km}$ depth, and smaller velocity increases at 32 and $38 \mathrm{~km}$ depth. The results were simplified into a 5-layer model and input into an alternating depth and velocity FBI (Tomfohrde, 1998, Fig. 6.12). 


\section{Discussion-Moho Depths}

The primary goal of this study was to utilize the receiver function method to determine crustal structure in Taiwan. In particular, we are concerned with the Moho depths beneath selected stations. In this section, we present the results for 9 different observed receiver functions at the 6 modeled stations from the Taiwan Seismic Network. These results are presented in Figure 11. The final simplified velocity models are corrected for station elevation. We first treat each station individually and then compare the results to velocity profiles constructed from the tomographic models given by RAU and WU (1995). Stations are extrapolated to the nearest profile along the strike of the 4 major geologic provinces. Locations for

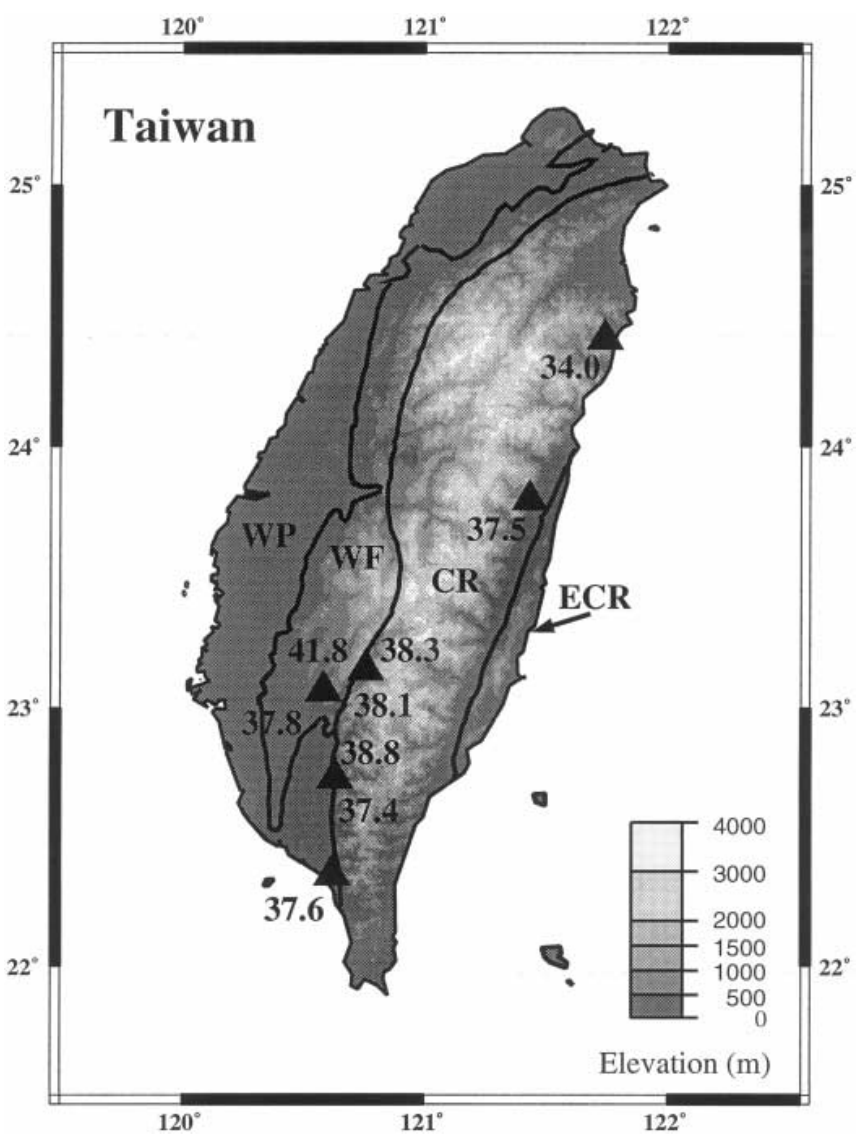

Figure 11

Moho depths at selected stations of the Taiwan Seismic Network from frequency-band inversion. Stations are noted by triangles. Refer to Figure 1 for station names. Values for the north and south backazimuths are labeled above and below each station, respectively. 


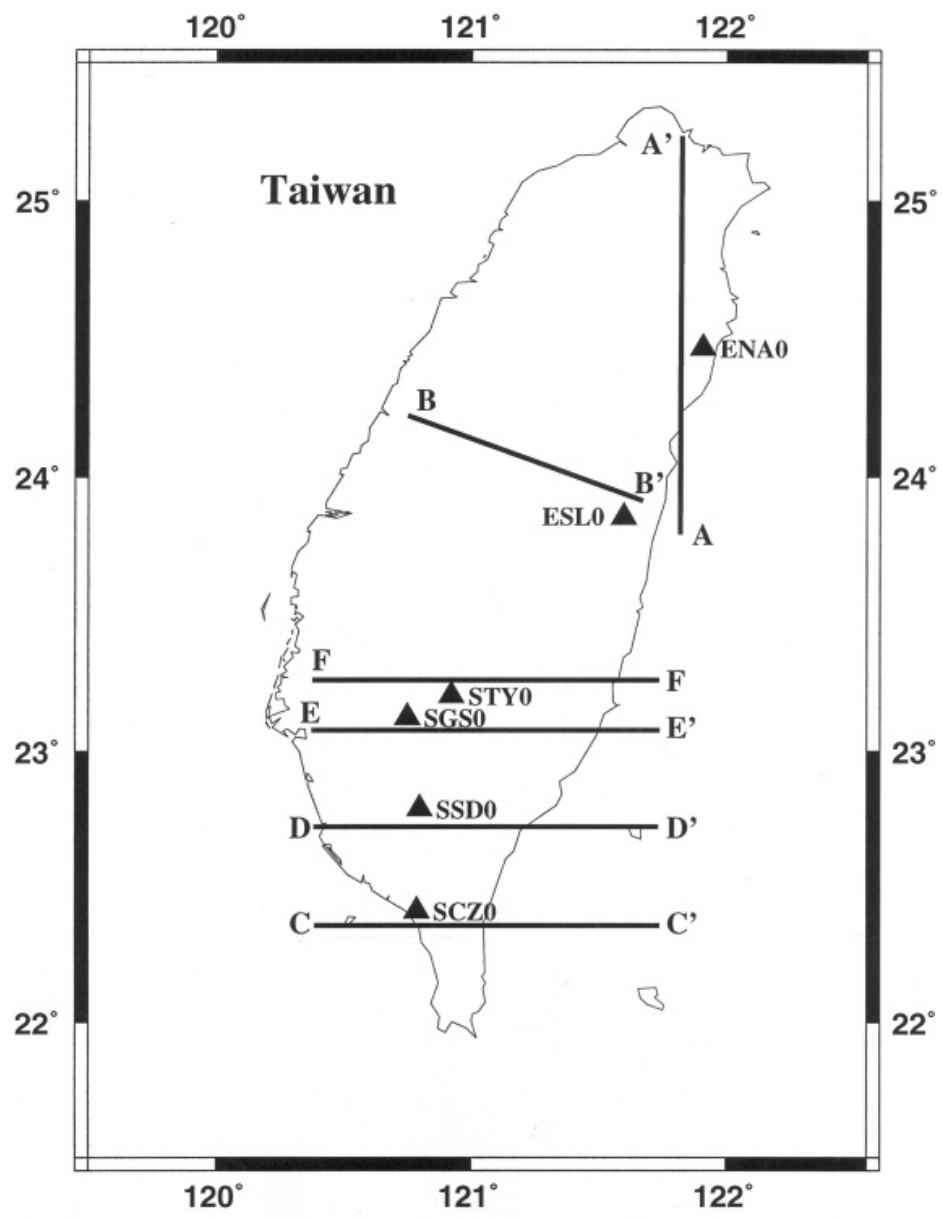

Figure 12

Locations of stations and RAU and WU (1995) velocity profiles shown in Figure 13. Stations are labeled and shown by triangles.

each velocity profile in Figures $13 \mathrm{~A}-\mathrm{F}$ are shown in Figure 12 along with station locations, noted by triangles and labeled. For each station, $P$-wave velocity contours are shown at 5.0, 5.5, 6.0,6.5, 7.0,7.5, 7.8, and $8.0 \mathrm{~km} / \mathrm{s}$ and the 7.5, 7.8 and $8.0 \mathrm{~km} / \mathrm{s}$ are used as bounds for the Moho, based on the tomography study of RAU and WU (1995). Thereafter results are compiled for the different geologic provinces and compared to the refraction results of MA and SoNG (1997).

Station ENA0 is located in northeastern Taiwan (Fig. 1) and has a calculated Moho depth of $34.0 \mathrm{~km}$ below sea level. This station is located at $75 \mathrm{~km}$ along the A-A velocity profile of RAU and WU (1995). Figure 13A displays the velocity profile $\mathrm{A}-\mathrm{A}^{\prime}$ and the triangle symbol represents station ENA0. To the right is 
shown the $P$-wave velocity model obtained from the final $S$-wave velocity derived from the receiver function inversion and assuming a Poisson solid. A vertical line is drawn directly beneath the station and a horizontal line is drawn at the calculated Moho depth for this station. The intersection of these lines occurs between the 7 and $7.5 \mathrm{~km} / \mathrm{s}$ contours, which is shallower than the $38 \mathrm{~km}$ depth where the $7.8 \mathrm{~km} / \mathrm{s}$

A)

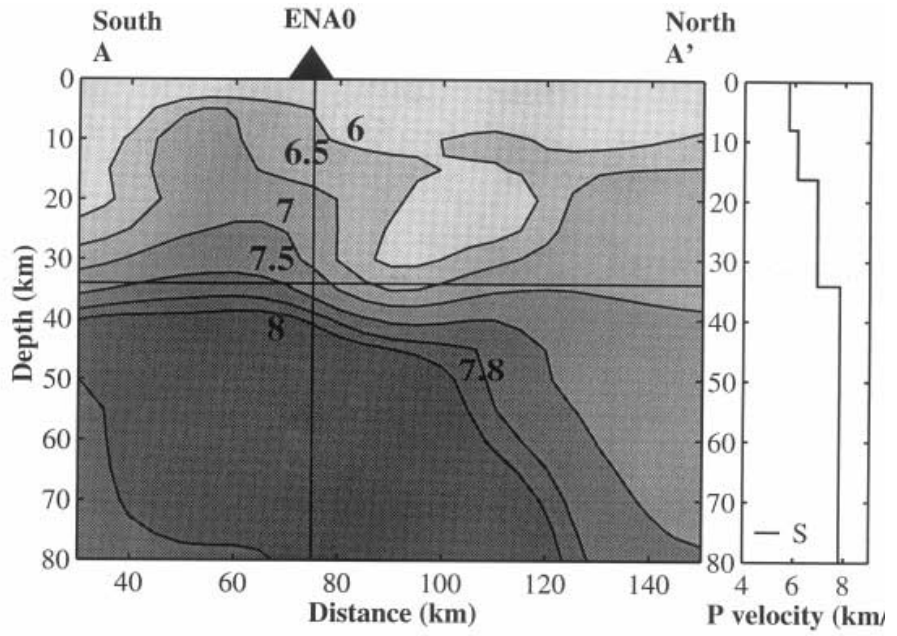

B)

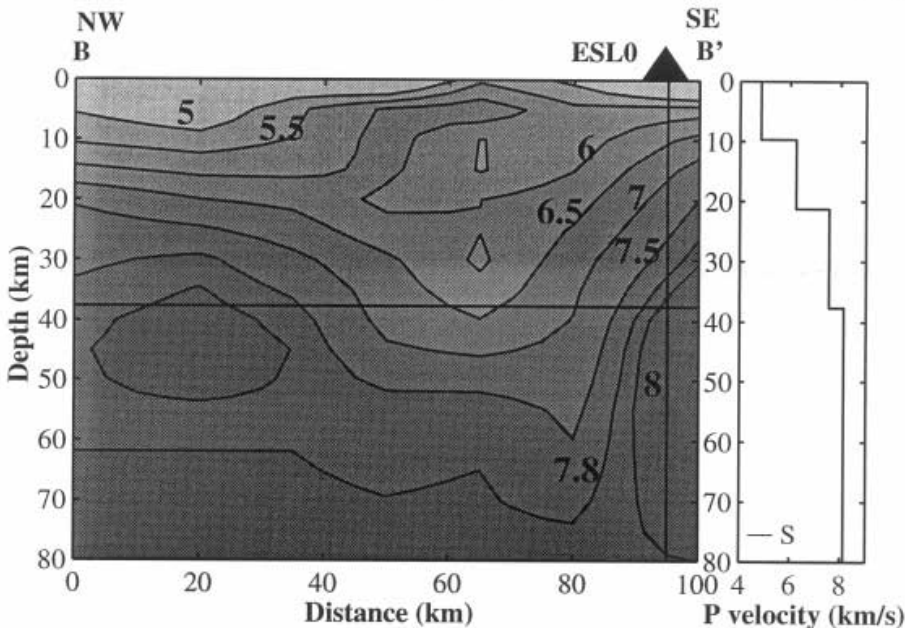

Figure $13 \mathrm{~A}, \mathrm{~B}$

Velocity profiles derived from the tomographic model of RAU and WU (1995). For stations A) ENA0 and B) ESL0, the final inversion results are shown on the right side of each plot. Velocity profiles are contoured at $5,5.5,6,6.5,7,7.5,7.8$, and $8.0 \mathrm{~km} / \mathrm{s}$. Grey shading is added to help identify each contour line. A triangle is shown along each profile at the position of the respective station and a vertical line is drawn directly below each station. The Moho depth calculated at each station is shown with a horizontal line. Profile locations are shown in Figure 12. 

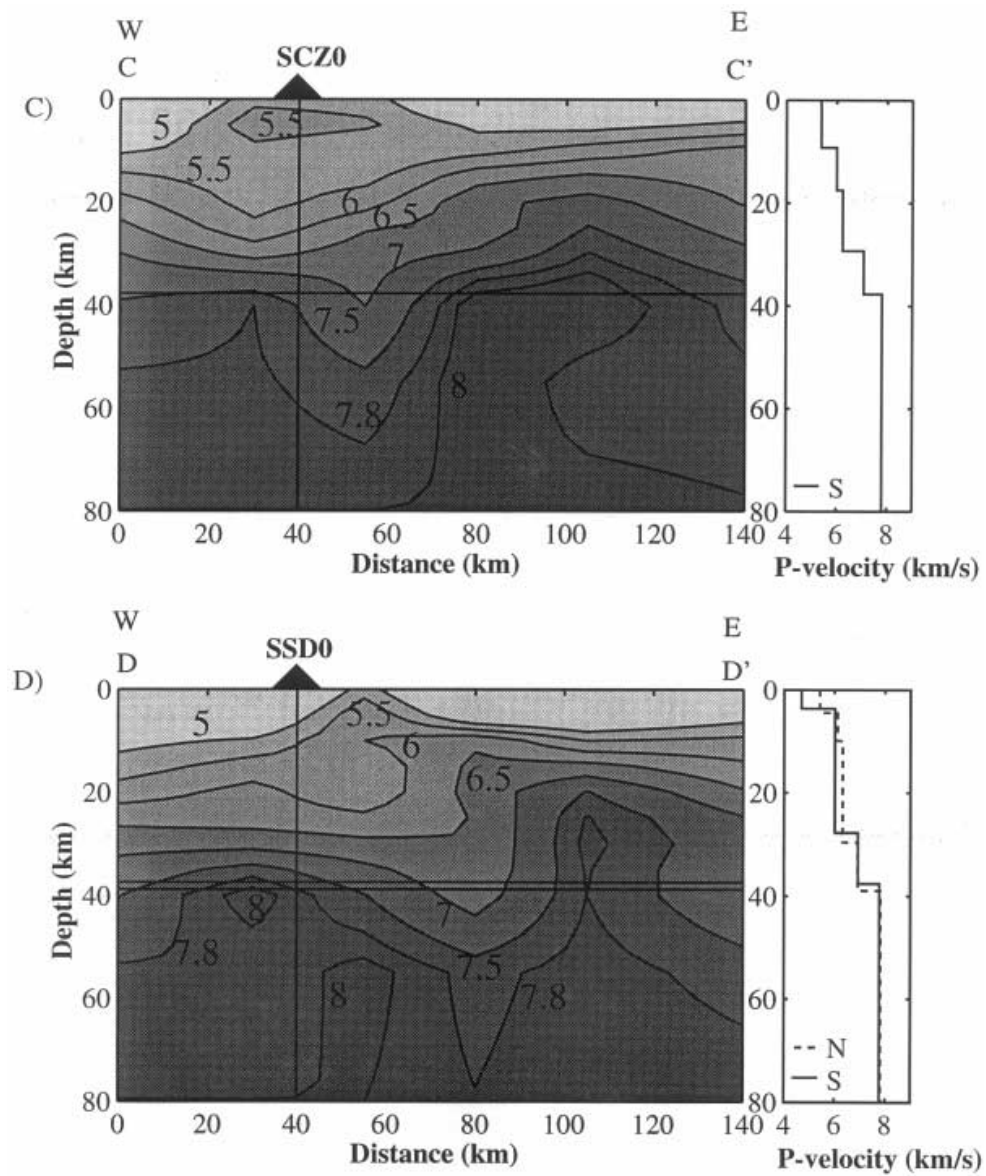

Figure 13C,D

Velocity profiles derived from the tomographic model of RAU and WU (1995). For stations C) SCZ0 and D) SSD0, the final inversion results are shown on the right side of each plot. Velocity profiles are contoured at $5,5.5,6,6.5,7,7.5,7.8$, and $8.0 \mathrm{~km} / \mathrm{s}$. Grey shading is added to help identify each contour line. A triangle is shown along each profile at the position of the respective station and a vertical line is drawn directly below each station. The Moho depth calculated at each station is shown with a horizontal line. Profile locations are shown in Figure 12.

contour intersects the vertical line. This may be due to the fact that the events used to obtain the receiver function for this station are to the south and as can be seen from Figure 13A, the 7.5 and $7.8 \mathrm{~km} / \mathrm{s}$ contours shallow somewhat immediately to the south of station ENA0.

Another station on the eastern flank of the central mountain range is station ESL0. This station is close to the $95 \mathrm{~km}$ mark of the B-B' profile calculated from the tomographic results of RAU and WU (1995) and the location of the profile is shown in Figure 12. In Figure 13B, a vertical line is drawn directly below this 
station and a horizontal line is drawn at $37.5 \mathrm{~km}$ depth, the calculated Moho depth for ESL0. On the velocity profile, the horizontal and vertical lines intersect immediately below the $8.0 \mathrm{~km} / \mathrm{s}$ contour. This matches the layer 4 velocity of 8.1 $\mathrm{km} / \mathrm{s}$ calculated from frequency-band inversion.

Station SCZ0 is the southernmost station modeled and is shown in Figure 13C. This station is located at $40 \mathrm{~km}$ along the $\mathrm{C}^{-\mathrm{C}^{\prime}}$ profile (see Fig. 12 for location) calculated from the tomographic study of RAU and WU (1995). This station is on the western edge of the southern Central Range. A vertical line is drawn directly below the station and a horizontal line is drawn at $37.6 \mathrm{~km}$ below sea level, corresponding to the Moho depth calculated for this station. The two lines intersect above the 7.5 and $7.8 \mathrm{~km} / \mathrm{s}$ contours, which are at depths of 40 and $55 \mathrm{~km}$ in this profile. One reason for this difference may be the extension of subduction of the Eurasian plate below the Philippine Sea plate under the southern portion of Taiwan. Also, as pointed out by Wu et al. (1997), the station coverage in the south tip of Taiwan is poor and hence the RAU and WU (1995) model is less well resolved in the southernmost part of the island.

The station SSD0 is located south of the $\mathrm{D}^{-\mathrm{D}^{\prime}}$ profile calculated from the tomography results of RAU and $\mathrm{WU}$ (1995) at a distance of $40 \mathrm{~km}$ along the profile (Fig. 13D) and is on the boundary of the Coastal Range and Western Foothills geologic regions (Fig. 1). A vertical line is drawn directly below the station and two horizontal lines are drawn corresponding to the Moho depths for the north and south backazimuths ( 38.8 and $37.4 \mathrm{~km}$ depth below sea level). The intersection of these lines occurs near the intersection of the $7.8 \mathrm{~km} / \mathrm{s}$ contour and the calculated values match the tomographic results of RAU and WU (1995) well.

Station SGS0 is located in the Western Foothills region (Fig. 1) and we were able to obtain receiver functions for the north and south backazimuth ranges. We project the station onto the E-E' velocity profile calculated from the results of RAU and $\mathrm{WU}$ (1995) and it is located $35 \mathrm{~km}$ along the profile (Fig. 13E). A vertical line is drawn directly below the station and two horizontal lines are drawn at 37.8 and $41.8 \mathrm{~km}$ depth, corresponding to the Moho depths calculated for the north and south backazimuths. The horizontal line at $37.8 \mathrm{~km}$ depth intersects the vertical line at the $7.8 \mathrm{~km} / \mathrm{s}$ contour. The $4 \mathrm{~km}$ difference seen between the 2 backazimuths may be due to local variations in the Moho to the north and south of this station.

Station STY0 is also on the boundary between the Central Range and the Western Foothills. This station occurs at $55 \mathrm{~km}$ along the velocity profile F-F' calculated from the tomographic results of RAU and WU (1995) and is shown in Figure 13F. Estimates of the Moho depth obtained for both north and south backazimuth ranges are 38.3 and $38.0 \mathrm{~km}$ below sea level and are shown with horizontal lines. These lines intersect the vertical line drawn directly below the station near the $7.8 \mathrm{~km} / \mathrm{s}$ contour and match the tomographic results of RAU and Wu (1995) well. 
Table 1 separates the stations by the geologic terrain within which they are located. The thinnest crust appears to be along the eastern coast of Taiwan, as indicated by stations ESL0 and ENA0. The remaining stations are aligned along the western margin of the Central Mountain Range in southern Taiwan. Seven of the nine estimates had Moho depths which were between 37 and $39 \mathrm{~km}$. Note that stations STY0 and SSD0 are listed in both due to being sited on the boundary between the Central Range and the Western Foothills. With the exception of ENA0, all of the values for the Moho depth in the Central Range are within the

E)
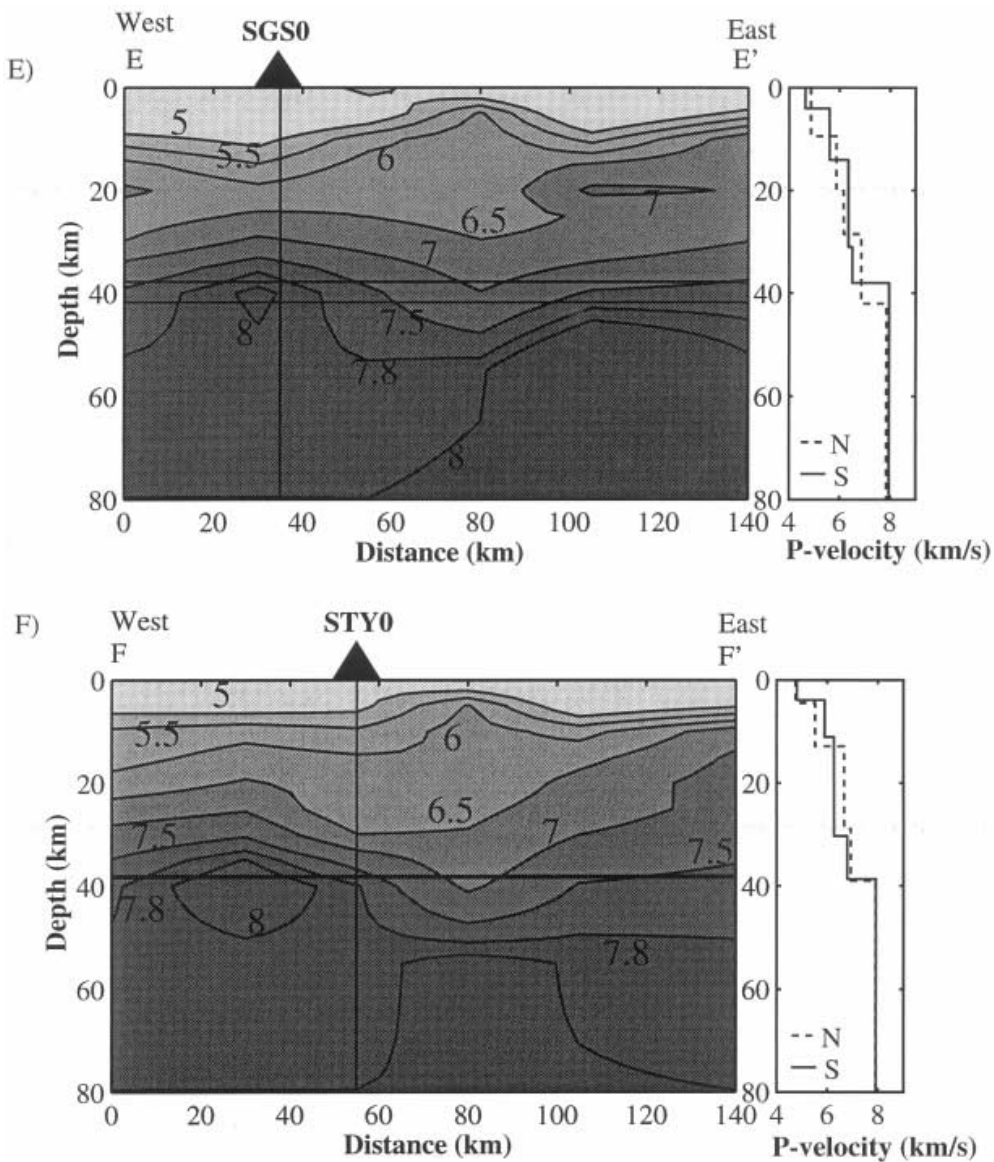

Figure 13E,F

Velocity profiles derived from the tomographic model of RAU and WU (1995). For stations E) SGS0 and F) STY0, the final inversion results are shown on the right side of each plot. Velocity profiles are contoured at 5, 5.5, 6, 6.5, 7, 7.5, 7.8, and $8.0 \mathrm{~km} / \mathrm{s}$. Grey shading is added to help identify each contour line. A triangle is shown along each profile at the position of the respective station and a vertical line is drawn directly below each station. The Moho depth calculated at each station is shown with a horizontal line. Profile locations are shown in Figure 11. 
Table 1

\begin{tabular}{|c|c|c|}
\hline & Western Foothills & Central Range \\
\hline ENA0-South & & 34 \\
\hline ESL0-South & & 37 \\
\hline SCZ0-South & 38 & \\
\hline SGS0-North & 42 & \\
\hline SGS0-South & 38 & \\
\hline SSD0-North & 39 & 39 \\
\hline SSD0-South & 37 & 37 \\
\hline STY0-North & 38 & 38 \\
\hline STY0-South & 38 & 38 \\
\hline Average* & $38 \mathrm{~km}$ & $38 \mathrm{~km}$ \\
\hline Overall average* & & \\
\hline MA and SoNG (1997) & $35 \mathrm{~km}$ & $42 \mathrm{~km}$ \\
\hline
\end{tabular}

* Excluding ENA0.

same range as the Western Foothills. Upon further examination of the location of the stations, this is not surprising. It has been suggested that there is a deeper root below the Central Range. Note that the stations are all outside of, or along the edge of the Central Range. Therefore, the results presented here are more indicative of the crust around the Central Range, and not the depth below the Central Range itself. The results at station ENA0 are approximately $4 \mathrm{~km}$ less than the average for all the other stations. One complicating factor below this station is the subduction of the Philippine Sea plate below the Eurasian plate. It has been recognized that the subduction along the Ryukyu Trench to the northeast can be extended below the northeast portion of Taiwan (ROECKER et al., 1987; RAU and WU, 1995; WU et al., 1997). The subducting slab can be seen in profile A-A $\mathrm{A}^{\prime}$ in Figure 13A by following the 7.5 and $7.8 \mathrm{~km} / \mathrm{s}$ contours to the north.

Also listed in Table 1 are the refraction results of MA and Song (1997). They report Moho depth for the Western Foothills and Central Range to be 35 and $42 \mathrm{~km}$, respectively. The average Moho depth for all stations modeled in this study is $38 \pm 1 \mathrm{~km}$ below sea level. Station ENA0 is not included in the average due to its proximity to the subduction zone in northern Taiwan. The uncertainties in Moho depth are derived from the uncertainties of the individual layer thicknesses for the final inversion step. These uncertainties incorporate prior uncertainties of the layer thicknesses and layer velocities. 


\section{Conclusions}

With the upgrade of the Taiwan Seismic Network in 1991, high quality three-component data are available and provide an excellent opportunity to study crustal structure beneath Taiwan. By using careful data analysis to increase data quality, we were successful in applying the receiver function technique to teleseismic data recorded by the short-period Taiwan Seismic Network. However, the use of short-period data and the filtering parameters for this study has lead to a somewhat "ringing" appearance of the individual filtered receiver functions resulting from the interference of phases, especially those from the upper crust. Nonetheless, the interpreted Moho phases are readily identified and modeled reasonably well in all cases. With the recent deployment of selected broadband stations, these new data will hopefully provide more detailed results for the structure beneath Taiwan in future studies. Nonetheless, useful preliminary results can still be obtained by using careful data analysis of the available short-period data from the Taiwan Seismic Network.

Radial and transverse receiver functions were obtained at six stations from the Taiwan Seismic Network. The transverse receiver functions from those stations indicate the possible presence of scattering from laterally varying structures or anisotropy. However, the agreement of results for north and south backazimuths show that these complications are within the uncertainties for those stations. Due to azimuthal limitations, effects due to anisotropy and dipping layers were not constrained and only the radial receiver functions were analyzed using horizontal plane layers to provide estimates of the vertically varying isotropic structure beneath these stations.

To improve convergence, we have used an inversion procedure termed frequency-band inversion or FBI. FBI is a multiple inversion procedure which uses band-pass filtering with sequentially higher low-pass corner frequencies to stabilize the iterative waveform inversion. The larger wavelength structure is determined first and more detail is included as the upper cutoff frequency is increased in subsequent frequency bands. The motivation of the frequency-band inversion is to help stabilize the inversion procedure, and is described in more detail by TOMFOHRDE (1998). However, the multiple frequency-band inversion requires more computation time than a corresponding single frequency band inversion.

For application to the Taiwan data, a 20-layer model was first constructed with seismic velocities derived from the prior tomographic models of RoECKER et al. (1987) and RAU and WU (1995) and inverted using a velocity-only frequency-band inversion. The resulting models were then simplified to 4 to 5 layer models and the simplified models were used as initial models for an alternating depth and velocity frequency-band inversion. For all the stations, the $P s$ phases are modeled reasonably well, however some phases later in the waveform were less well modeled by the inversion. They may result from stacking problems in the data or various structural 
complexities not modeled such as scattering from heterogeneities or anisotropy. The RMS misfit for the final simplified models increases somewhat with respect to the corresponding 20-layer model. However, the number of model parameters for each case decreased by a factor of 2, and the RMS misfit remained less than the average data errors.

The resulting Moho depths for the simplified models, corrected for station elevation, are shown in Figure 11 and listed in Table 1. Seven of the 9 estimates had Moho depths which were between 37 and $39 \mathrm{~km}$. With the exception of station ENA0, the results for stations within the Western Foothills are similar to those located along the western and eastern boundaries of the Central Range province. Consequently the results for the Central Range given here are more indicative of the crust adjacent to the Central Range, and not below the Central Range itself. We have compared our results to velocity profiles calculated from the tomographic model of RAU and WU (1995), and each of the stations with the exceptions of SCZ0 and ENA0 match well with the tomographic results.

For station SCZ0, active subduction below the station may affect our Moho depth results. Also, as WU et al. (1997) pointed out, station coverage in the southern tip of Taiwan is poor and the tomographic model is less well resolved below station SCZ0. For station ENA0, the Moho depth calculated for this station is $4 \mathrm{~km}$ less than others within the Central Range province. However, the effects of active subduction of the Philippine Sea plate to the north of this station and slightly shallower Moho depths to the south of the station in the tomographic models may account for this discrepancy.

The average Moho depths for all stations modeled is $38 \mathrm{~km}$ below sea level. Station ENA0 is not included in the average due to its proximity to the subduction zone in northern Taiwan. The average value of $38 \mathrm{~km}$ is between the values for the crustal thickness for the Western Foothills and Central Range, 35 and $42 \mathrm{~km}$, respectively, obtained by MA and SoNG (1997).

\section{Acknowledgements}

We extend appreciation to Y. H. Yeh for permitting us access to CWB-TTSN data and to R. J. Rau for providing his tomographic results. We also thank W.-P. Chen and John Cassidy for their constructive comments on the manuscript. This research was supported by NSF grants EAR 94-05167 and EAR 96-14772.

\section{REFERENCES}

Ammon, C. J., Randall, G. E., and Zandt, G. (1990), On the Nonuniqueness of Receiver Function Inversions, J. Geophys. Res. 95, 15,303-15,318. 
Ammon, C. J., and ZAndt, G. (1993), Receiver Structure beneath the Southern Mojave Block, California, Bull. Seismol. Soc. Am. 83, 737-755.

CAssidy, J. F. (1992), Numerical Experiments in Broadband Receiver Function Analysis, Bull. Seismol. Soc. Am. 82, 1453-1474.

CAssidy, J. F., and Ellis, R. M. (1993), S-wave Velocity Structure of the Northern Cascadia Subduction Zone, J. Geophys. Res. 98, 4407-4421.

Clouser, R. H., and Langston, C. A. (1995), Effect of Sinusoidal Interfaces on Teleseismic P-wave Receiver Functions, Geophys. J. Int. 123, 541-558.

Ho, C. S. (1979), Geologic and Tectonic Framework of Taiwan, Mem. Geol. Soc. China 3, 57-72.

Hsu, V. (1990), Seismicity and Tectonics of a Continent-Island Arc Collision Zone at the Island of Taiwan, J. Geophys. Res. 95, 4725-4734.

Hu, G., and Menke, W. (1992), Formal Inversion of Laterally Heterogeneous Velocity Structure from P-wave Polarization Data, Geophys. J. Int. 110, 63-69.

Langston, C. A. (1977), Corvallis, Oregon Crustal and Upper Mantle Receiver Structure from Teleseismic $P$ and $S$ Waves, Bull. Seismol. Soc. 67, 713-724.

LAngston, C. A. (1979), Structure Under Mount Rainier, Washington, Inferred from Teleseismic Body Waves, J. Geophys. Res. 84 (B9), 4749-4762.

Levin, V., and PARK, J. (1997), P-SH Conversions in a Flat-layered Medium with Anisotropy of Arbitrary Orientation, Geophys. J. Int. 131, 253-266.

MA, K. F., and Song, D. R. (1997), Pn Velocity and Moho Depth in Taiwan, J. Geol. Soc. China 40, $167-184$.

MA, K. F, WANG, J. H., and ZhaO, D. (1996), Three-dimensional Seismic Velocity Structure of the Crust and Uppermost Mantle beneath Taiwan, J. Phys. Earth 44, 85-105.

McNamara, D. E., and Owens, T. J. (1993), Azimuthal Shear Wave Velocity Anisotropy in the Basin and Range Province Using Moho Ps Converted Phases, J. Geophys. Res. 98, 12,003-12,017.

Owens, T. J., ZANDT, G., and TAYlor, S. R. (1984), Seismic Evidence for an Ancient Rift beneath the Cumberland Plateau, Tennessee: A Detailed Analysis of Broadband Teleseismic P Waveforms, J. Geophys. Res. 89, 7783-7795.

Randall, G. E., and Owens, T. J. (1994), Array Analysis of the Large-aperture Array of the 1988-89 PASSCAL Basin and Range Passive-Source Seismic Experiment, Geophys. J. Int. 116, 618-636.

RAU, R. J., and Wu, F. T. (1995), Tomographic Imaging of Lithospheric, Structures under Taiwan, Earth Planet. Sci. Lett. 133, 517-532.

Rau, R. J., Wu, F. T., and Shin, T. C. (1996), Regional Network Focal Mechanism Determination Using $3 D$ Model and SH/P Amplitude Ratio, Bull. Seismol. Soc. Am. 86, 1270-1283.

Roecker, S. W., Yeh, Y. H., and Tsai, Y. B. (1987), Three-dimensional P-and S-wave Velocity Structures beneath Taiwan: Deep Structure beneath and Arc-continent Collision, J. Geophys. Res. 92, $10,547-10,570$.

Suppe, J. (1981), Mechanics of Mountain Building and Metamorphism in Taiwan, Mem. Geol. Soc. China 23, 67-90.

Suppe, J., The active Taiwan mountain belt. In The Anatomy of Mountain Ranges (eds. Schaer, J. P., and Rogers, J.) (Princeton Univ. Press, Princeton, NJ 1987) pp. 277-293.

Teng, L. S. (1990), Geotectonic Evolution of Late Cenozoic Arc-continent Collision in Taiwan, Tectonophysics $183,57-76$.

Tomfohrde, D. A. (1998), Crustal Structure in Taiwan Using Frequency-band Inversion of Receiver Function Waveforms, MS Thesis, Purdue University, West Lafayette, IN.

Wu, F. T., Rau, R. J., and SalzberG, D. (1997), Taiwan Orogeny: Thin-skinned or Lithospheric Collision?, Tectonophysics 274, 191-220.

Zhang, J., and Langston, C. A. (1996), Array Observations of the Shear-Coupled PL Wave, Bull. Seismol. Soc. Am. 86 (2), 538-543. 